\title{
APROXIMACIÓN SEMIÓTICA AL ESPACIO DE LA CASA EN LA LITERATURA TURCA Y ESPAÑOLA (ESTAMBUL DE ORHAN PAMUK Y NADA DE CARMEN LAFORET)
}

\author{
NESRIN KARAVAR \\ Universidad de Barcelona \\ nesrinkaravar3@hotmail.com \\ ORCID: 0000-0001-9225-9244
}

\section{RESUMEN}

En este trabajo analizo la casa de Nada y la casa de Estambul de la literatura de posguerra, comparando viviendas de dos culturas diferentes, con una aproximación semiótica y espacial.

PALABRAS CLAVE: espacio interior, literatura turca, literatura española posguerra, semiótica

SEMIOTIC APPROACH TO THE SPACE OF THE HOUSE IN TURKISH AND SPANISH POST-WAR LITERATURE (ISTANBUL'S OF ORHAN PAMUK AND NADA'S OF CARMEN LAFORET)

\section{ABSTRACT}

This article provides an analysis of the Nada's house and the Istanbul house of post-war literature, comparing housing of two different cultures, with a semiotic and spacial approach.

KEYWORDS: Interior space, Turkish literature, Spanish literature, Post-war, Semiotic

\section{INTRODUCCIÓN: ESTADO DE LA CUESTIÓN}

La literatura comparada no solo estudia las relaciones entre la literatura, sino entre otras áreas como arquitectura, religión, gastronomía, etcétera. Es decir, también es la comparación de un tema específico en dos obras parecidas de dos culturas o naciones diferentes en la literatura. Como veremos los escritores que viven en un mismo período histórico tienen elementos comunes, aunque sean de distintas culturas y cada uno escriba con su estilo personal. Este tipo de comparación se amplía la literatura, tanto en términos geográficos como genéricos. Este aspecto de los estudios comparativos es el que ofrece el mayor potencial desde el punto de vista de la teoría literaria o ambiental y puede llevar a una comprensión de los aspectos sociales.

La época en que empiezan a escribir y se desarrolla la personalidad de Carmen Laforet y de Orhan Pamuk son diferentes. Laforet es una de las escritoras de la literatura de posguerra española de las primeras décadas del s. XX. Mientras que Pamuk es el escritor postmoderno/contemporáneo turco de las últimas 
décadas del s. XX y principios del XXI, aunque los periodos literarios de los dos escritores son diferentes, la vivienda donde ha transcurrido la infancia de Pamuk coincide con el de la literatura de posguerra turca en la década de los 50. En donde la casa, como resto de la guerra, era de color gris como, por casualidad, el color de las imágenes de las portadas de los dos libros, como se ve en la figura I y figura II. De esta manera, el espacio adquiere mayor valor sémico por su relación con los colores y con los personajes. Las observaciones de un ámbito vivido y personalizado, un marco escénica, adquiere significación, y se capta así el espacio con una mirada semántica. En ambas novelas de la literatura turca y española la huella de la guerra se incorpora no solo a sus viviendas, sino al paisaje, a sus calles también dentro de la literatura y la semiótica:

Gracias a esa permanencia en la literatura de todos los tiempos han llegado a formar parte de la misma musicalidad del lenguaje que las mantiene vivas. Sus lugares comunes reaparecen en los textos, formando algunas melodías básicas que despliega la literatura temporalmente (...) Algunas de estas palabras que representan ideas éticas y morales, recreadas literariamente, están especialmente relacionadas con el marco de la ciudad, del territorio, y con el sentido que hemos dado a sus distintos espacios. A través de este interés por los espacios habitados, literatura y ética establecen un pacto sutil con la idea de arquitectura, con el sentido que lo arquitectónico adquiere frente al lenguaje" (Llorente, 2015: 214).

Pues, ¿Qué puede decirnos el interior de las casas? Se podrá decir que la gente ya vive en una casa $y$, por tanto, no necesitaba saber nada más. Aunque parece que los viajeros extranjeros de Estambul han pensado así y, como decía Pamuk, han olvidado escribir sobre el interior de las casas:

Los viajeros extranjeros se ven obligados a olvidar, especialmente en Estambul, que lo que moldea una ciudad es tanto su apariencia exterior como el interior de las casas y el paisaje de los espacios cerrados (2017: 320).

O, como Llorente también llama atención en este detalle y dice:

Una nueva literatura, dirigida a la gente común que empieza a leer de manera más general, aunque producida por autores cultivados, donde la vida cotidiana, el sujeto común, la banalidad de la existencia y sus pequeñas peripecias son el tema central. Pero esta literatura dirigida al entretenimiento de las gentes comunes tampoco ofrece una mirada minuciosa al espacio real, material, cotidiano, al interior habitado (...) La primera literatura europea escrita para el público que cuenta las historias de su propia gente no acierta a explicar los espacios donde esas historias se desarrollan (2015: 353).

En este artículo, elaborado muchos años después de la época de los viajeros extranjeros de Estambul vamos a analizar, dentro del ámbito de la literatura comparada, las características culturales del espacio interior reflejadas por el autor en Estambul (2005) de Orhan Pamuk (1952) y Nada (1944) de Carmen Laforet (1921). Una especie de casa formada por distintas ideas de la literatura no de la 
arquitectura que, inevitablemente, no cabe en una sola casa. Esta casa solo cabe en la cabeza de quienes la imaginan, y construir las casas literarias en el entorno real de Laforet y de Pamuk seria necesariamente construir tan sólo una parte de estos argumentos. Como afirma otra vez Llorente:

Sin embargo, la mirada hacia el espacio que habitan hombres y mujeres, la conciencia de ser en el espacio, y los pequeños debates que fluyen en torno a esta conciencia, vivida desde la cotidianidad, brillan definitivamente en la literatura latina (2015: 215).

Ambas observaciones literarias del espacio dibujan una de las descripciones más intensas de un melancólico y emotivo retrato de la casa de diferentes religiones y culturas en dos ciudades lloradas y solas de la posguerra: una casa de Estambul (en las décadas de los 40, los 50 y los 60) y en una casa de la Barcelona (antes de 1944). Disponemos de traducciones en los dos sentidos: Estambul Ciudad y recuerdos al castellano (2017, por Rafael Carpintero de Penguin) y Nada al turco (2007, por Zerrin Yanıkkaya). Pero en nuestro trabajo utilizamos Nada al castellano (2014, de Austral).

\section{ESPACIO DOMÉSTICO DE POSGUERRA BARCELONÉS DE NADA Y ESTAMBULÍ DE ESTAMBUL}

"No entréis en las viviendas que no sean las vuestras hasta que hayáis asegurado el permiso de sus residentes" (Corán, 24:27).

La comunicación no-verbal es muy extensa, ya que abarca la amplia franja de canales de comunicación que llenan los espacios de todos nuestros sentidos, cada uno con un origen, percepción, procesamiento e interpretación muy diverso, desde una sofá hasta un instrumento o tazas de café. Debemos reconocer y ver su heterogeneidad considerando la naturaleza de las sensaciones, de los mensajes, como también de los puntos cerebrales encargados de procesar su información.

Si cualquier cosa puede definirse como ciudad, entonces la definición corre el riesgo de no significar nada. La ciudad es el espacio que determina las formas de comunicación sea verbal o no-verbal. Y es difícil conocer esta comunicación en el mundo de la ciudad sin conocer sus representaciones humanas de su espacio habitado. Este conocimiento de las personas de la ciudad ayudaría con la expresión peirceana interpretant la relación entre lo verbal y lo visual de la ciudad. Una ciudad configura a las personas el interior de las casas, que consiste en mucho más que una aglomeración de edificios como afirma el arquitecto francés Le Corbusier (1887-1965) de quien Pamuk utilizó uno de sus dibujos de silueta de Estambul en su libro (p. 54): “Busco con verdadero afán esas casas que son casas de hombres y no casas de arquitectos" (1978:25). Una ciudad que nunca está completa, y que no puede ser producto de una sola visión como dice Pamuk: "a mí me daba la impresión de que cada piso era un universo completamente 
diferente, un país completamente distinto"(2017:29). Las ciudades no son creaciones estáticas, sino que cambian y se desarrollan. Para conocer una ciudad hay que saber algo de la gente que vive en ella, y de aquellos que la construyeron. Los muebles, los objetos, las fotografías de los miembros de las viviendas establecen otra relación con el lugar, es como mantener el aire de la escena teatral, hasta que resulta imposible separar aquéllos de ésta. Aunque los miembros de las viviendas pasan, sin embargo sus fotografías y sus muebles permanecen para recordar el rostro del hombre, su mirada, pero tambien ocultan el espacio y hablan del resto de las cosas vividas como Andrea recordaba su visita de niñez con su madre en el piso de Aribau y Pamuk en su edificio familiar. Ambas casas han pasado a ser como museos melancólicos con los objetos que otorgan contenido semántico a los diferentes escenarios. El Museo de la Inocencia, como se ve en la figura V, creado por Orhan Pamuk e inaugurado en 2012 en Estambul, introduce la casa como el lugar de la colección, acercando la casa al museo y, por tanto, al espacio colectivo (Monteys, 2017:15). Como repite Pamuk: "fantasear a la sombra del museístico salón"(2017: 29), o Andrea lo siguiente: "de las noches de invierno con sus húmedas melancolías"(2014: 236). Como señala el arquitecto holandés Habraken:

Una vivienda solo será una vivienda, no cuando tenga cierta forma, no cuando satisfaga ciertas condiciones que fueron redactadas después de laborioso estudio, no cuando ciertas dimensiones y requisitos han sido tenidos en cuenta, en cumplimiento de las ordenanzas municipales, sino solo y exclusivamente cuando la gente se mete a vivir en ella (1975: 3738).

Recordando a los arquitectos barceloneses Xavier Monteys y Pere Fuertes cuando afirmaban que:

La gente, las personas que habitan los edificios, siguen siendo, en el fondo, los grandes olvidados en la arquitectura residencial. Sin embargo, una casa es una vivienda más la gente que la habita y los objetos que guarda (2001:14).

El fenómeno de la globalización interviene también en la concepción de la ciudad y del espacio doméstico, homogenizando estos en todo el mundo, trascendiendo toda frontera y aplastando las costumbres y las culturas. Las leyes que rigen la distribución de los espacios en la edad contemporánea en el barrio de Nişantaşı y en la calle Aribau son iguales: el comedor, el dormitorio del matrimonio, el de los hijos. Muchos de los muebles y electrodomésticos se repiten en muchas de ellas. Pero, sin embargo, son exclusivos de un lugar, de una cultura. Por ejemplo, las tazas tradicionales para tomar café turco en la casa de Pamuk era imposible que existiera en la casa de Andrea. Dibuja esta escena tradicional de café turco así: "A veces veo por una ventana a una mujer sola sentada a una mesa leyendo su fortuna en los posos del café" (2017: 320). Y café en la casa de Barcelona: “la cafetera exprés y sacaba no sé de dónde unas mágicas tazas (...)" 
(Laforet, 2014: 93). Después de esta escena tradicional y femenina, Pamuk explica el mobiliario, los objetos como dan una imagen fiel de las estructuras familiares y sociales de la época occidental como la siguiente:

Usaban la ropa, los muebles y los últimos descubrimientos de la tecnología occidental (desde los exprimidores de naranjas hasta las maquinillas de afeitar eléctricas) que podían comprarse en Europa con su dinero, se los enseñaban unos a otros y eran felices (2017: 224225).

En las casas nuevas de Turquía, las modas del estilo Imperio Otomano estaban ya caducadas. Pero, como los platos de cerámica de Nicea colgados de la pared (Pamuk, 2017:319) o un Corán (Pamuk, 2017: 20) o tomar la bebida alcohólica turca raki aunque en la mesa está el vodka también (Pamuk, 2017: 25) hace pensar en lo que realmente es común a las viviendas y lo que no lo es. Y en cambio, Pamuk, como buen turco que busca elementos autóctonos, también echa de menos la antigua riqueza ornamental otomana desaparecida por influjo europeo:

Entre los dieciséis y los dieciocho años, por un lado, como occidentalizado radical quería que la ciudad y yo mismo fuéramos absolutamente occidentales, pero por otro quería pertenecer al Estambul que amaba con mi instinto, con mis costumbres y mis recuerdos (2017:371).

A partir de la segunda mitad del siglo en España y en Turquía va apareciendo un nuevo orden burgués como consecuencia de la modernización de la economía. Esto quiere decir que las dos ciudades estarán en buena parte construidas por edificios de viviendas, que ya no desentonarán por su calidad y decoración del resto de los edificios antiguos, como lo vemos en el edificio de Pamuk en la figura III como nuevo modo de habitar en Estambul: "El edifico Pamuk fue construido en un lateral del amplio solar de lo que en tiempos había sido el jardín de una gran mansión de un bajá en Nişantaşı" (2017: 40).

Las viviendas familiares se construyeron para las clases media y media alta, para esa burguesía acomodada que buscaba viviendas confortables, amplias y cómodas, dentro de la tónica europea imperante (Serrano, 2006:14). En la época del imperio otomano la mayoría de los ricos tenía sus mansiones de madera en la costa del Bósforo como los ricos de la clase barcelonés las tenían hacia la montaña:

Pons vivía en una casa espléndida al final de la calle Muntaner. Delante de la verja del jardín-tan ciudadano que las flores olían a cera y a cemento- vi una larga hilera de coches (Laforet, 2014: 240).

Pero los nuevos ricos de Estambul de la época de la República para sentirse más occidentales preferían vivir en los edificios y barrios más modernos de la arquitectura neoclásica occidental del siglo XIX, tal como el espacio interior de la casa familiar. Pamuk, por ejemplo, lo describe: 
En mi infancia, para los nuevos ricos y para la burguesía estambulí que empezaba a prosperar, las mansiones del Bósforo no eran lugares nada atractivos. Las casas antiguas no estaban protegidas contra el viento del nordeste ni el frío del invierno, y calentarlas era difícil y costoso. Como los nuevos ricos de la época de la República no eran tan poderosos como los bajás otomanos y se sentían más occidentales si vivían en los barrios de los alrededores de Taksim en pisos que daban al Bósforo de lejos, no compraron las antiguas mansiones de Bósforo a las familias otomanas alejadas del poder. (...) Así fue como, antes de los setenta, en los que la ciudad creció a toda velocidad, desaparecieron mientras yo era aún un niño la mayor parte de los palacetes y mansiones de madera del Bósforo (2017: 7778).

Esta internacionalización de las viviendas se parece también en los movimientos literarios como decía Goethe: "Hoy la literatura nacional no significa gran cosa, se acerca la época de la literatura del mundo" (Guillen, 2015: 65).

Ambos libros realistas y con afirmada intención histórica o documental y son best-sellers, en los que hoy en día, cuando los lectores los leen, son como testigos de las transformaciones palpables en Estambul y en Barcelona en la segunda mitad del siglo debidas a los cambios económicos y sociales pero, sobre todo, se ofrece un cuadro significativo que estos cambios sociales con llevan la tragedia de muchas familias de las clases medias de la burguesía turca y española. Las formas de reflejo especular del arte y literatura, que recogieron este sistema complejo de vida y espacio construido, pueden ofrecer una manera de considerar los cambios que aporte datos esenciales a nuestra idea de ciudad en la cultura (Llorente, 2015:374). La literatura de Pamuk y Laforet leyeron la casa como unos outsiders, pero no una casa ficticia, o falsa, sino una casa vivida entre experiencia y espacio transformada en materia novelesca. Proporcionan un informe vital, importante a la hora de comprender las ciudades de posguerra. Como señala el arquitecto australiano Rapoport:

Estas viviendas, al ser la expresión directa del cambio de valores y modos de vida, se convierten en un tema muy fructífero de estudio. El valor de esta clase de estudio es que proporciona una gama de variables en diferentes culturas, así como extremos más amplios; una mayor interpretación de la gama de alternativas posibles (1972:24).

\section{ENTRE CALLE Y CASA}

"Y los llevó por camino derecho/ para que pudieran llegar a ciudad habitada" (Salmos 107, 4-7).

El proceso de aprendizaje de Andrea y de Orhan, consiste en descubrir la relación de contigüidad entre la casa y las calles de Barcelona y de Estambul. La casa para ellos no simboliza el retiro. Se refiere al retiro como un lugar imaginario, aunque sólo sea mentalmente, una situación de la que se puede disfrutar desde la casa o desde la calle también. El retiro en ambos libros está en todas partes. Sus paseos sirven para enseñarles en la ciudad los mismos elementos de la escena doméstica. 
Escribía Orhan recordando su niñez: “(...) plaza de Taksim, la plaza más grande de mi infancia, el centro de mi mundo, alrededor del cual he vivido desde que era niño" (2017:257). O, con las palabras de Andrea, "entrar en la calle de Aribau era como entrar ya en mi casa" (2014:157). El hogar y la calle tienden entre sí un nuevo dialogo que las reúne. Sus aprendizajes consisten en descubrir que la imagen del hogar como ambiente de las relaciones harmónicas es falsa, los pisos fríos estilo museo (Pamuk, 2017:339) donde Barcelona y Estambul son dos caras de la misma inquietud. Dos viviendas íntimas de dos sociedades en color blanco y negro según los dos escritores que han perdido el equilibrio económico, su identidad, y que se enfrentan al desplome de su norte espiritual. Y quizás, esta inquietud común y el color gris de los pisos y de las calles de las dos ciudades provocaban la creatividad literaria de ambos escritores. Al respecto, decía Nietzsche:

La disciplina del sufrimiento, del gran sufrimiento (...), su inventiva y valentía en el soportar, perseverar, interpretar, aprovechar la desgracia, así como toda la profundidad, misterio, mascara, espíritu, argucia,, grandeza que le han sido donados al alma: ¿no le han sido donados bajo sufrimientos, bajo la disciplina del sufrimiento? (1986: 171-172).

Con siglos de diferencia ambos escritores afirman lo que dijo Nietzsche: “El olor especial, el gran rumor de la gente, las luces siempre tristes, tenían para mí un gran encanto" (Laforet, 2014:7). Y como subrayó Pamuk no escapar de esta ciudad triste ha provocado su creatividad:

Hay autores, como Conrad, Nabokov o Naipaul, que han conseguido escribir con éxito cambiando de lengua, de nación, de cultura, de país, de continente e incluso de civilización. Y sé que, de la misma forma que su identidad creativa ha ganado fuerza con el destierro o la emigración, lo que a mí me ha determinado ha sido permanecer ligado a la misma casa, a la misma calle, al mismo paisaje, a la misma ciudad (2017:16).

A partir del siglo XIX en Europa la arquitectura doméstica aparece en la literatura con publicaciones sobre la higiene, sobre los trabajos del ama de casa, la decoración del hogar, economía doméstica en las grandes ciudades como Paris, Madrid o Barcelona (Serrano, 2006:11). Pamuk y Laforet, dentro de este tipo de la literatura, construyen sus espacios interiores alrededor de las tensiones que caracterizan el cambio de una época a otra desarrollando una cultura de lo doméstico en el interior de una casa. Construyendo sus propias memorias y al dar los primeros pasos en una ciudad que se convertirá en el escenario de sus monografías. Habría, por consiguiente, cierta correlación entre la literatura y el espíritu general de su época. Sobre los efectos del entorno Rapoport señala así:

Los efectos del entorno en los hombres pueden ser directos o indirectos. En este último caso el entorno proporciona claves (señas) que se utilizan para interpretar la situación social, y de esta definición situacional se deducen los efectos producidos en el ser humano. En este sentido, el entorno puede ser considerado como una forma de comunicación no verbal (2003: 26). 
Las dos obras son productos de sus tiempos. En derredor había desolación, ruinas, y debían acostumbrarse a un nuevo estilo de vida, o mejor dicho, a una nueva identidad. Como se nota en las palabras siguientes de Pamuk:

Siento como si la oscuridad de la noche fuera a cubrir la pobreza de la vida, las calles y los objetos, y que, mientras respiramos tranquilos por fin en casa, en nuestros cuartos, en nuestras camas, nos entregaremos a sueños y fantasías hechos de las antiguas riquezas, las construcciones desaparecidas y las leyendas de ese Estambul ahora tan lejos (2017: 50).

Parece que quedaron por siempre traspasadas en ello, porque en varias de sus narraciones posteriores aparece directa o indirectamente el espejismo de estas amarguras. En un sentido similar se expresa el psiquiatra Carlos Castilla del Pino (1922-2009) que dice "toda casa, cualquier casa, no es metáfora, sino prolongación fáctica de nuestra identidad". ${ }^{1}$ El hogar es símbolo de un mundo que es espejo de nosotros mismos es como espejo interior de Laforet y de Pamuk, el yo soy del individuo. En la expresión de Adolf Loos (1870-1933); "hacia el exterior la casa no debe decir nada" (Gravagnuolo, 1988:80). Es como un microcosmos de macrocosmos o símbolo de símbolos. O es como los siguientes versos del poeta sufí turco Yunus Emre (1238-1321): «Hay un yo en mí, más allá de mí».2

En los dos escritores el origen del sentimiento de amargura se sustenta en la pobreza y en la sensación de derrota de las calles y de las casas. Los autores conocieron a muchos de los que integran esta familia de la calle de Aribau o del barrio Nişantaşı o del Bósforo que han vivido los desastres de la guerra y se han empobrecido también como consecuencia de ella, como la casa de Nada: "Una vivienda modesta, desde luego con menos pretensiones burguesas y artísticas, pero limpia, plácida y acogedora" (Caballé, 2010:131). O como la casa de la familia de Pamuk, una amplia familia de aquellas que en tiempos otomanos habitaba una misma mansión, como los Pamuk, ingenieros que habían hecho dinero en los años treinta con la construcción de ferrocarriles, habían convertido en una casa de apartamentos para las distintas ramas familiares. En años posteriores diría Pamuk: "mientras la gran familia, nuestra familia nuclear se iban desmenuzando y empobreciendo (...) como el desplome del Imperio otomano"(2017:29). Estas sensaciones han hecho que a estos libros se les considere como una representación típica de cierta sensibilidad de posguerra:

\footnotetext{
${ }^{1}$ Carlos Castilla del Pino, «Bajar al sótano», en Luis Fernández Galiano (comisario), El espacio privado. Cinco siglos en veinte palabras, Madrid, Ministerio de Cultura, 1990.

2 http://www.yunusemre.gov.tr/index.php/eserleri/siirleri/siirlerin-devami/severim-ben-senicandan-iceri, [20/12/2017].
} 
Las manadas de perros callejeros, sobre los que escribieron con el mismo entusiasmo todos los viajeros occidentales que vinieron a la ciudad en el siglo XIX, de Lamartine a Nerval o Mark Twain, también alimentan esa sensación mía de blanco y negro, enriqueciéndola con una cierta inquietud (2017: 59).

Para entender esa época es necesario comprender que los desastres de la guerra han sido profundos. El catedrático español Pozuelo afirma así:

(...) La enorme importancia que en la cultura presente española tiene el memorialismo, las vidas contadas, los testimonios del yo. Podría decirse que vivimos una eclosión de narraciones sobre la vida privada. Quiero destacar que este fenómeno ha provocado que la Guerra Civil preferentemente sea perspectivizada desde la primera persona, también cuando se trata de memoria novelística (...). Casi siempre, en cambio, son voces particulares o perspectivas de focalización interna las que gobiernan la estructura, lo cual pueda explicarse por esa concordancia con la eclosión memorialista y el pacto pragmático de testimonio histórico contraído con el lector (2017:251).

Anna Caballé señala lo siguiente:

Tradicionalmente, las guerras han sido una inmejorable fuente de escritura: desde Troya hasta las modernas especulaciones sobre una posible guerra nuclear, la literatura ha bebido en las fuentes de los enfrentamientos militares, tanto reales como imaginarios (...). En realidad siempre ocurre así: la historia viva acaba transformándose en la materia del arte (1986:14).

Nada y Estambul no son libros objetivos, sino radicalmente subjetivos por sus realismos intimistas:

Me habría gustado escribir así este libro porque cuenta toda una vida como si la hubiera vivido otro y porque se parecería a un sueño agradable que debilitaría la voz y la voluntad propias. Pero ese hermoso lenguaje de cuento de hadas no me resulta convincente porque muestra esta vida como una preparación para otra más real y luminosa en la que nos despertaremos más tarde como si nos despojáramos de un sueño (Pamuk, 2017: 19).

Como afirma Laforet refiriendo el personaje Andrea que es un personaje no ficticio sino real, como Orhan de Estambul con sus propias palabras:

Nada la escribí en dos fases. La primera, en ambiente y el tipo de personajes, era mi vida en Barcelona y por lo tanto no necesitaba -preparar-un personaje de mi edad y viviendo en un tiempo determinado y una determinada ciudad que yo viví (Caballé, 2010: 127).

Realizan sus reflexiones sobre la casa, sobre las calles, sobre las personas, la soledad desde distintos y parecidos puntos de vista. Pero con una observación común como un testigo busca reconstruir la memoria de una época trabajando con la mirada del recorrido de los cuerpos como podemos analizar en sus palabras como afirma Laforet, "es tan delicioso y tan asombroso siempre 
observar la vida!"3 Y sigue Pamuk, "me gusta observar y escribir la gente de la ciudad".

Así, Laforet y Pamuk habían acertado a conjugar la observación realista de las casas de posguerras y un mundo lleno de sugestiones personales. Dan a ésta una desnuda gravedad humana con un lenguaje semiótico. Aquí están dos sociedades no solo dos ciudades, sino dos familias reales, descritas, como diría el profesor Gonzalo Sobejano, sin caer por la pendiente de la novela rosa (1975:153).

Y sigue de este modo:

Los novelistas "observadores" se distinguen por imprimir a sus relatos un sesgo cronístico y anecdótico, propio de quienes durante un tiempo históricamente importante, se apresuran a registrar las experiencias personales para informar a la posteridad (1975: 55).

Con sus observaciones asombrosas hacen hablar a la ciudad, hacen hablar al espacio de lo interno. Laforet y Pamuk ofrecieron a sus lectores un lenguaje transparente opuesto a la opacidad de los signos convencionales, capaz de revelar la substancia verdadera de las cosas. En sus obras narran muchas veces sin reservas de sus vidas cotidianas pero con un mérito en ello, no una imagen de sí mismos vergonzante, sino una sinceridad como valor literario.

Laforet es una escritora que en su novela Nada reflexiona y busca su identidad como una mujer libre, el sentido de su vida y la fusión de los contrasentidos que desde su adolescencia se le van presentando en una época de grandes limitaciones para una mujer, como decía Carmen Martin Gaite: "que para la mujer la tierra es la familia" (2017:65). Laforet, como joven de la posguerra, estaba harta de la vida vigilada y buscaba su libertad fuera de la casa: "Los niños de postguerra, que lo que queríamos era ir al cine o que nos compraran una bicicleta, estábamos hartos de la vida sacrifica, vigilante"(2017:23). Se puede decir que su novela participa de las mismas inquietudes, preocupaciones y obsesiones, y que, a lo largo de su vida, van siguiendo su propia evolución personal. Evidentemente su tono de esperanza, decepción, nueva esperanza, va oscilando. Al respecto dice la escritora chilena Graciela Illanes Adaro:

Hay una correlación entre su vida y sus obras. El cambio de ciudades, de residencia le ha dado cada vez nuevos horizontes para el tema de sus narraciones. Esto no quiere decir nada en relación con su poder de crear, el que depende de una penetrante observación y de una aguda captación de lo psicológico. Los ambientes de cada lugar conocido los han ido cogiendo, y los han motivado en pro de la creación artística, especialmente el clima de los años posteriores a la guerra, su repercusión en seres y en cosas, todo esto ha influido de manera grande en su espíritu y, por lo tanto, en su obra, así es que, pasados muchos

${ }^{3}$ Carmen Laforet, “El roce humano”, en Destino de 27 de junio de 1951. 
años, estas obras podrán servir para reconstruir mucho del sentir de esos días. Serán documentos que, indirectamente, ayudarán algo a la historia (1971:12-13).

Orhan Pamuk describe la vida de la calle y casa bajo de la nueva República turca, que trae consigo la tensión entre Oriente y Occidente, entre tradición y modernidad, tensión de construir una nueva identidad turca republicana y europeísta que todavía se encuentra presente en las casas pero como un hombre sin buscar su libertad personal por la seguridad de ser hombre, no como una mujer turca de su época como podemos observar en una página del periódico estambuli del año 1974:

Si ve a una mujer hermosa por la calle no la mire con odio, como si fuera a matarla, ni con excesivo deseo. Si sus miradas se cruzan, limitase a sonreír y a seguir adelante apartando la mirada (2017: 166).

Las consecuencias de la guerra se materializaban en lo cotidiano: la vida de los nuevos ricos, empobrecimiento de los antiguos ricos, libros, pinturas, melancolía, silencio para llegar a conseguirlo las múltiples dimensiones ocultas del lado no verbal de la vida. En la tradición literaria turca este proceso tiene su inicio en la novela Paz (1948) de Ahmet Hamdi Tanpınar (1901-1962). Dice al respecto Orhan Pamuk: "Ahmet Hamdi Tanpınar sería el primero en desarrollar una imagen y una literatura de la ciudad" (2017: 272).

Laforet y Pamuk, los dos, vienen de familias cultas y barrios cultos y artísticos de la ciudad en donde se refleja este ambiente artístico, cuadras en las dos viviendas. Laforet de abuelo materno pintor y de padre pintor y arquitecto decía una vez que: "Mi infancia estuvo llena de referencias a pintores y escultores" (Caballé \& Rolon, 2010:25). De hecho el tratamiento que recibe la pintura en ambos libros tiene la sensibilidad de quienes se sienten muy cerca de ella:

El piso de Cihangir, cuyas paredes fueron llenándose de cuadros, acabó por convertirse en una pequeña galería, pero nadie, ni siquiera mis padres, se pasaba por allí para decirme lo maravillosa que era mi obra (Pamuk, 2017: 315).

Y sigue la escena de la pintura en la vivienda de la calle Aribau: "Juan pintaba trabajosamente y sin talento, intentando reproducir pincelada a pincelada aquel fino y elástico cuerpo" (Laforet, 2014: 91).

Este enfoque familiar al espacio interior de la casa permite también acercarse a las viviendas como los cambios de las dos sociedades. Proceso de conocimiento de la dinámica de la sociedad, que se le revela por medio de la vivencia del cotidiano de sus casas. Lo cierto es que todo el vivir humano en el continente europeo y el Medio Oriente se ha visto alterado radicalmente y de forma veloz, en especial desde la segunda mitad del siglo pasado. Desde entonces, el rostro del mundo es bien diferente. En palabras de Pamuk, "es necesario entender un poco más ese sentimiento que toda la ciudad parece 
compartir como un destino común"(2017:110). O, "la amargura que despedía aquella cultura muerta, aquel imperio hundido, se encontraba por todos lados" (2017: 43). Afirma Laforet también esta tristeza de pérdida lo siguiente: "El olor de melancolía frente al horizonte abierto del mar" (2014: 176). O, "el olor especial, el gran rumor de la gente, las luces siempre tristes" (2014: 71). La mirada por la ventana de sus casas no es algo solamente pintoresco y anecdótico sino también es simbólico... Es la manera de mirar a través de la historia y del pasado de Estambul y Barcelona. La melancolía reflejada en las viviendas y en las calles de los dos escritores son las melancolías más allá de lo personal. Es el sentimiento común de dos ciudades de la posguerra que está explicada con la simbología de los edificios sentimentalmente destruidos y con los ambientes pesados. Pero, quizás, esta amargura de Estambul se encontraba por todos los lados de la ciudad, no solo por la posguerra o derrota y pérdida del Imperio Otomano sino también por sus imperios anteriores. Estambul pasó de ser una capital cosmopolita, a una ciudad turquificada y occidentalizada, cuyos habitantes asistían de las huellas de grandes culturas y grandes civilizaciones, pero cortaron los lazos con su pasado:

\begin{abstract}
Algunas ciudades como Estambul miden sus historias con múltiples identidades, iluminando así las diversas agendas políticas y culturales de sus líderes. Estambul, que antes se llamó Constantinopla, y antes aun Bizancio, ha sido capital de tres distintos. Cobró forma con los fragmentos supervivientes de la civilización griega, romana, bizantina y otomana que la construyeron (Sudjic, 2017:58).
\end{abstract}

Observar la organización del espacio íntimo entre dos culturas en la mitad del siglo XX en una Turquía y en una España económicamente y en un nivel de desarrollo social parecido antes de entrar España en la Unión Europea, significa antes de los tiempos de la globalización cuando todavía la identidad nacional no estaba globalizada en los dos países que representan a la burguesía barcelonesa y estambuli, clase que se consolidaría hegemónica desde la Guerra Civil y desde la nueva República turca. La consecuencia más general de las guerras en la literatura española y turca ha sido la adopción de un nuevo realismo:

Después de la guerra civil, y esto todo lo que podemos llamar realismo, entendiendo por realismo la atención primordial a la realidad presente y concreta, a las circunstancias reales del tiempo y del lugar en que se vive. Ser realista significa tomar esa realidad como fin de la obra de arte, y no como medio para llegar a ésta: sentirla, comprenderla, interpretarla con exactitud, elevarla a la imaginación sin desintegrar ni paralizar su verdad, y expresarla verídicamente a sabiendas de lo que ha sido, de lo que está siendo y de lo que puede ser (Sobejano, 1975:24).

En la casa de la abuela Laforet y de la familia de Pamuk con un contenido semántico están las huellas del pasado: enriquecimiento y empobrecimiento de 
los propietarios de tierras y los fallidos proyectos de inspiración aristocrática. Están los rasgos del pasado cercano y del presente. Pamuk que habla de su casa, pero cuidado, de una casa real y no de ese mágico país de las Mil y una noches que nos imaginamos en España. Sino en un país como señala el novelista Tanpinar:

Para nuestra generación, Estambul es algo muy distinto de lo que era para nuestros abuelos, incluso para nuestros padres. No acude a nuestra imaginación investida de un manto imperial con brocados de plata y oro, ni la vemos a través del marco de la religión. La luminosidad que rebosa la palabra es, sobre todo, la de la nostalgia y la de los recuerdos del pasado que elegimos según nuestro estado de ánimo (...) Hasta tal punto que podemos afirmar que es esa añoranza la que le otorga a Estambul la faz fundamental que hoy vive en nosotros. Y es la propia ciudad la que la alimenta en nosotros hasta en sus particularidades más simples (2018: 141).

La vida doméstica de Pamuk, por la influencia de su cultura turca-otomana, es siempre una imagen de la totalidad; su forma señala el modo en que el hombre se integra en el universo. Como en todas las culturas tradicionales y sagradas como decía Mircea Eliade: "la casa es una imagen del mundo y representa el mundo" (2001:106). Y para Pamuk también la casa es el corazón de la vida. Es el centro inmutable alrededor del cual se desarrolla la vida. Dice al respecto:

Cincuenta años después sigo viviendo en el mismo edificio. Más que por las habitaciones y la belleza de los muebles, la casa es importante para mí porque es el centro del mundo que tengo en la cabeza (2017: 109).

Ante esta descripción es imposible no recordar que para la cultura turca el hogar o la estructura interna es el lugar que envuelve, unifica y protege como una imagen del paraíso. La omnipresencia de lo sagrado en la vida cotidiana del musulmán expresada en su hogar, es la que disuelve cualquier distinción entre el cuerpo y el espíritu: en ello hallamos la diferencia radical entre la planificación del espacio interior moderno y la tradicional. En este aspecto contrastan unas culturas con otras. Decía el investigador intercultural estadounidense Edward Hall (1914-2009) que;

Los individuos policrónicos, como los árabes y turcos, que casi nunca están solos, ni siquiera en su casa, hacen usos distintos de la protección. Tienen relaciones con varias personas al mismo tiempo y están constantemente involucrados unos con otros (1978: 27).

Las narraciones en ambos libros poseen una riqueza textual y el gran valor semántico que adquieren los objetos propios del espacio, de las calles y de los personajes de dos ciudades. Para ambos autores el espacio pasa de ser un simple elemento decorativo con su capacidad de semiotizaciones, con personajes y espacios de gran riqueza. Con la aproximación semiótica en ambos libros el espacio es un elemento que se convierte en un signo que crea sentidos semánticos y pragmáticos. En cuanto a la caracterización del espacio, del objeto o de la calle 
se transforma en el análisis semiótico de las narraciones. Pamuk, a veces narra a sus padres como una fotografía colgada de la pared: "había veces en que hablaban mientras continuaban inmóviles como si posaran para una fotografía" (2017: 318). Subraya frecuentemente los gestos de los personajes: "De repente el gordito que no hacía ni media hora lloraba a lágrima viva porque se le había olvidado el cuaderno en casa, ahora cantaba feliz abriendo enormemente la boca" (2017: 153). Confesa también que le gustaba observar: "Me gustaba observar a mis compañeros mientras aparentaba cantar" (2017: 152). O, este valor semántico espacial en la habitación de Ramón funciona como una cámara: “Tenía una cama turca y, bajo la pequeña ventana enrejada, una mesa muy bonita llena de papeles $(\ldots)$ " (Laforet, 2014: 92). O, su interpretación gestual del señor no conocido: "Vi lucir en sus ojos una buena chispa de ironía" (2014: 155). Sus ámbitos pueden ser observados, puesto que el hombre ocupa un lugar concreto y se mueve a través de los espacios de Nada y de Estambul. La casa, la calle y los que habitan son ejes que posibilitan el desarrollo de la narración. Se observa los cambios, la tristeza, las pérdidas de la época posguerra a través de estos tres ejes. Sus significativas actuaciones gestuales hacia estos cambios en la vida cotidiana como describen en ambos libros:

(...) en cuanto se mencionaban cuestiones fundamentales como el amor, el cariño, la religión (...) todo el mundo se encerraba en el ensimismamiento y en una soledad patética (...) Luego se dejaban llevar por alguna melodía de la radio, encendían un cigarrillo y se retiraban en silencio a su mundo interior" (Pamuk, 2017. 219).

La abuela de Andrea simboliza la tradición que moralmente resiste a los cambios de la posguerra. Juan cuando acepta que Andrea pague una mensualidad por su habitación observamos la reacción verbal y no-verbal de la abuela como la siguiente:

La abuelita escuchó moviendo la cabeza con aire de reprobación, pendiente de los labios de Juan. Luego empezó a llorar.

-No, no, que no pague la habitación...que mi nieta no pague la habitación en casa de su abuela (2014: 158).

En fin, los dos escritores son portadores de su tiempo y de su ambiente y, mediante ellos se expresa una clase, una sociedad de Barcelona y Estambul: melancolía, tristeza y depresión. Los libros repiten hasta el final estos sentimientos cuando son presentados el interior de las viviendas y los personajes que la habitan. La imagen de la casa, de las calles y de la ciudad que los rodea crea sensaciones de angustia aparece ahora, en la lectura como cinematográficas de blanco y negro; color de la literatura posguerra. Aunque Andrea en su habitación, para cambiar este color, recitaba las bellas palabras del Avemaría en 
ambos ciudades el color de la realidad era gris: "Empecé a recitar las bellas palabras del Avemaría (...), que siempre me han parecido azules" (2014: 201).

\section{FIGURAS}

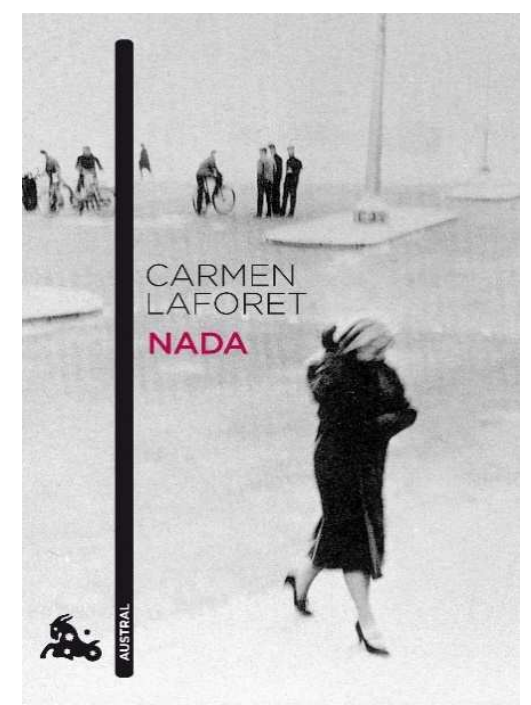

Figura I

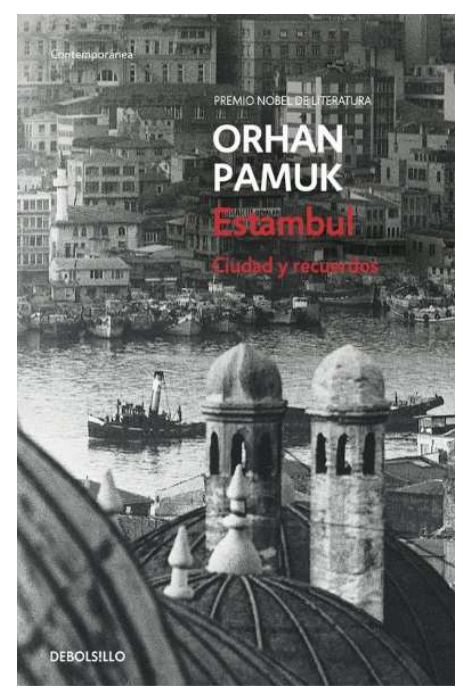

Figura II

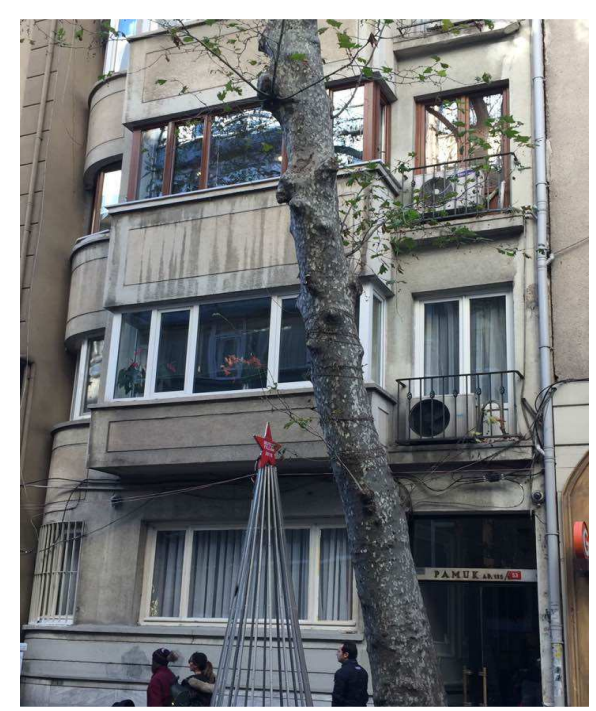

Figura III: La foto ha sacado por la misma autora en Estambul el 12 de diciembre de 2017. 


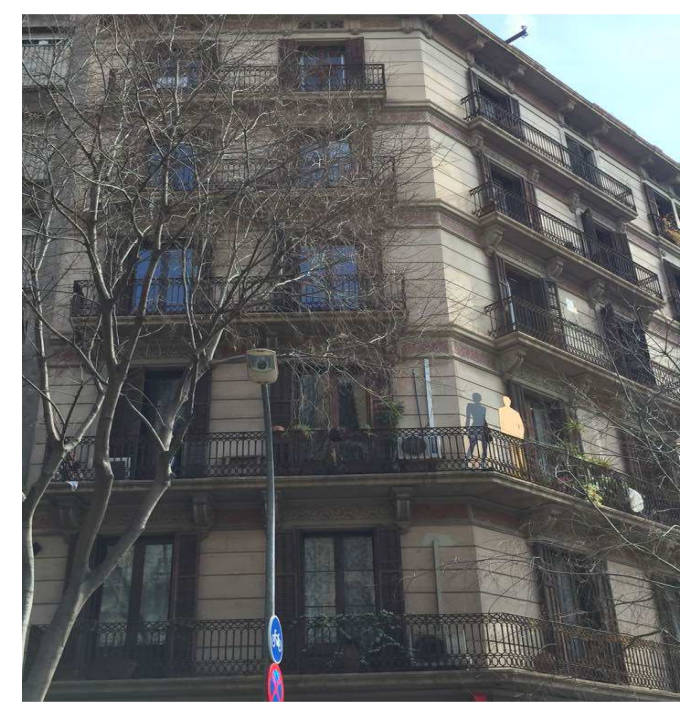

Figura IV: La foto ha sacado por la misma autora en Barcelona el 22 de febrero de 2018.

\section{BIBLIOGRAFÍA}

AdAro Illanes, G. (1971), La Novelística De Carmen Laforet. Madrid, Gredos.

CABAllé, A.; Rolon, I. (2010), Una mujer en fuga. Biografía de Carmen Laforet. Barcelona, RBA libros.

ELIADE, M. (2001), Nacimiento y renacimiento. Significado de la iniciación en la cultura human. Barcelona, Kairos.

FIENNES, W. (2017), Los gansos de las nieves. Mi viaje migratorio al gran viaje. Madrid, Errata Naturae.

GAITE, C., M. (2017), Usos amorosos de la postguerra español. Barcelona, Anagrama.

GRAVAGNUOLO, B. (1988), Adolf Loos, teoria y obras. Gipuzkoa, Nerea.

GIMÉNEZ SERRANO, C. (2006), La Casa. Evolución del espacio doméstico en España, Vol. 2 Edad contemporánea. Madrid, El Viso.

HABRAKEN, N.J. (1972), Soportes. Una alternativa al alojamiento de masas. Madrid, Alberto.

LAFORET, C. (2014), Nada. Barcelona, Austral.

Le CORBUSIER, (1978), Prologo americano, Precisiones respecto a un estado actual de la arquitectura y del urbanismo. Barcelona, Poseidón.

LLORENTE A., J. (2015), El octavo sentido. La comunicación, factor clave de la sociedad del siglo $X X$. Madrid, EDAF.

LLORENTE DiAZ, M. (2015), La ciudad: huellas en el espacio habitad. Barcelona, El Acantilado.

MONTYES, X.; FuERTES, P. (2001), Casa collage. Un ensayo sobre la arquitectura de la casa. Barcelona, Gustavo Gili.

MONTYES, X. (2017), LA calley la casa. Urbanismo de interiors. Barcelona, Gustavo Gili.

NieTZCHE, F. (1986), Mas allá del bien y del mal. Madrid, Alianza.

PAMUK, O. (2017), Estambul. Ciudad y recuerdos. Barcelona, Penguin Random House.

PozUelo Yvancos , J. M. (2017), Novela española del siglo XXI. Barcelona, Catedra.

RAPOPORT, A. (1972), Vivienda y cultura. Barcelona, Gustavo Gili.

RAPOPORT, A. (2003), Cultura, arquitectura y diseño. Barcelona, UPC. 
SANTA, A. (EDC.) (1988), Literatura y guerra civil. (Influencias de la guerra de España en las letras francesas y hispánicas). Barcelona, Promociones y publicaciones universitarias. SobejANO, G. (1975), Novela española de nuestro tiempo. Madrid, El Soto.

SUDJIC, D. (2017), El lenguaje de las ciudades. Barcelona, Ariel.

Tanpinar, A. H., Trad. Ortega Carpintero, R. (2014), Paz. Madrid, Sexto.

TANPINAR, A. H., Trad. Ortega CARpintero, R. (2018), Cinco Ciudades. Madrid, Sexto Piso.

Twitchell Hall, E. (1978), Más allá de la cultura. Barcelona, Gustavo Gili. 